\title{
Tryptophanase Synthesis in Escherichia coli: the Role of Indole Replacement in Supplying Tryptophan and the Nature of the Constitutive Mutation tnaR3
}

\author{
By R. M. EDWARDS $†$ AND M. D. YUDKIN* \\ Microbiology Unit, Department of Biochemistry, University of Oxford, Oxford OX13QU,UK
}

(Received 23 November 1983)

\begin{abstract}
The properties of the tryptophanase constitutive mutation thaR 3 have been investigated. It has previously been reported that mutants carrying thaR 3 grow poorly on medium that selects for constitutive expression of tryptophanase. Our results now show that this poor growth can be explained by the inability of tryptophanase to catalyse the synthesis of L-tryptophan from indole, pyruvate and ammonia at a rate sufficient to allow normal growth. Improved media for the characterization of tryptophanase constitutive mutants are described. The mutation tnaR3 rendered tryptophanase synthesis constitutive (at a differential rate that at $37^{\circ} \mathrm{C}$ is $30 \%$ of the fully induced wild-type) and not further inducible. Diploid studies showed that tnaR3 is cisdominant, but no evidence was found for any effect in trans. In addition to rendering tryptophanase synthesis constitutive, tnaR3 affects the response of tryptophanase synthesis to different growth temperatures.
\end{abstract}

\section{INTRODUCTION}

Tryptophanase [EC 4.1.99.1; L-tryptophan indole-lyase (deaminating)] is a catabolic enzyme that catalyses the degradation of L-tryptophan to indole, pyruvate and ammonia. In certain circumstances, tryptophanase can also catalyse the synthesis of L-tryptophan in the whole cell. Tryptophanase synthesis is induced both by L-tryptophan and by various analogues of L-tryptophan, and is very sensitive to catabolite repression.

Strains of Escherichia coli which have a lesion in tryptophan synthase [EC 4.2.1.20; L-serine hydro-lyase (adding indoleglycerol-phosphate)] can nonetheless grow by using tryptophanase to synthesize L-tryptophan, provided that indole and 5-methyl-DL-tryptophan are included in the medium and that the carbon source is not catabolite repressing (Peck et al., 1971). Thus a trpdeleted strain will grow on glycerol/minimal medium supplemented with indole and 5-methylDL-tryptophan. It has been hitherto assumed that the role of the 5-methyl-DL-tryptophan was solely to induce tryptophanase synthesis.

Regulatory mutations that affect tryptophanase synthesis have been isolated, either by omission of 5-methyl-DL-tryptophan from the selective media to select constitutive mutants or by the addition of a catabolite-repressing carbon source to select catabolite repression-resistant mutants (Yudkin, 1976; Taylor \& Yudkin, 1978). Some mutants are found to have the dual phenotype of constitutivity and catabolite resistance (Ward \& Yudkin, 1976). The majority of these regulatory mutations map close to tnaA, the structural gene for tryptophanase (Taylor \& Yudkin, 1978).

The $t$ naA gene and its putative regulatory region have been sequenced (Deeley \& Yanofsky, 1981). The sequence $5^{\prime}$ to the coding region shows a number of interesting features. There is a region showing close homology with the binding site for the 3',5'cyclic AMP-catabolite-sensitive gene activator protein complex (cAMP-CAP) present in the lac promoter. This is not surprising

† Present address: Searle Research Laboratories, High Wycombe HP12 4HL, UK. 
in view of the absolute dependence of tryptophanase synthesis on the presence of an intact cAMP-CAP system (Ward \& Yudkin, 1976). Another striking feature is the long (300 bp) region between the transcription start point and the tryptophanase initiation codon. Deeley \& Yanofsky (1982) have speculated on the involvement of some translational mode of control but could find no structure resembling that of the attenuator system found in the trp, phe and other biosynthetic operons. The same authors have also isolated a number of constitutive and catabolite repression-resistant mutations which map close to tnaA; some of these are suppressible by supC and yet none are complemented by plasmids carrying the tna $A$ region. Deeley \& Yanofsky (1982) suggest that these mutations may be in the gene for a trans-acting regulatory protein, but question whether a nonsense mutation in such a protein could overcome the requirement for cAMP-CAP binding.

In the present paper we examine the properties of tnaR3 (Taylor \& Yudkin, 1978), a mutation that causes constitutive expression of thaA but does not confer resistance to catabolite repression. It was selected as a mutation that allowed a trp-deleted strain to grow on glycerol/minimal medium supplemented with indole. thaR 3 has been shown to map very close to tnaAts6, a tryptophanase structural gene mutation, on the side distant from $b g l R$ (Taylor \& Yudkin, 1978). Enzyme assays suggested that it was a high-level constitutive mutation that rendered tnaA expression insensitive to the presence of inducer.

We now show, using an improved enzyme assay, that thaR 3 renders tnaA expression about $30 \%$ constitutive and indifferent to the presence of L-tryptophan. By constructing suitable strains we have obtained evidence suggesting that tnaR 3 is cis-dominant but not trans-dominant.

\section{METHODS}

Strains of bacteria and phages. These are described in Table 1 . The specialized transducing phage גimm 21 traA has been described previously (Borck et al., 1976).

Media. These were as described by Yudkin (1976) and Taylor \& Yudkin (1978). The medium used to select for $t_{\text {tna }}{ }^{+}$in $\operatorname{trpAC} 9$ backgrounds was that of Vogel \& Bonner (1956) supplemented with $0.2 \%$ glycerol, $5 \mu \mathrm{g}$ indole $\mathrm{ml}^{-1}$, and $50 \mu \mathrm{g} 5$-methyl-DL-tryptophan $\mathrm{ml}^{-1}$. Other supplements were used at concentrations described in the text.

Genetic techniques. These were as described by Yudkin (1976) and Taylor \& Yudkin (1978).

Tryptophanase assay. Samples of culture $(0.1-0.5 \mathrm{ml})$ were added to $1 \mathrm{ml}$ assay buffer $(0.1 \mathrm{M}$-potassium phosphate buffer $\mathrm{pH} 7.8,150 \mu \mathrm{g}$ pyridoxal phosphate $\mathrm{ml}^{-1}, 250 \mu \mathrm{g}$ bovine serum albumin $\mathrm{ml}^{-1}, 10 \mu \mathrm{M}-$ 2-mercaptoethanol, and $100 \mu \mathrm{g}$ chloramphenicol ml ${ }^{-1}$ ) containing about $10^{9}$ cells of MY281 (a mutant completely devoid of tryptophanase activity) which had previously been washed in phosphate buffer. The samples were collected in micro test tubes (Eppendorf) and kept on ice until ready for assay. The cells were deposited by centrifugation at $4{ }^{\circ} \mathrm{C}$ and resuspended in $1 \mathrm{ml}$ assay buffer. The centrifugation was repeated and the cells were finally resuspended in $1 \mathrm{ml}$ assay buffer. A $0.5 \mathrm{ml}$ sample of each sample was transferred to a glass scintillation vial. Toluene $(1 \mathrm{ml})$ was added to each vial in turn and the samples were shaken at $37^{\circ} \mathrm{C}$. After $5 \mathrm{~min}$ preincubation the reaction was started by the addition of $0.1 \mathrm{ml}$ assay mixture (assay buffer containing $10 \mathrm{mg}$ L-tryptophan $\mathrm{ml}^{-1}$ ). The reaction was stopped by the addition of $3.4 \mathrm{ml}$ Ehrlich's reagent. The colour was allowed to develop for $30 \mathrm{~min}$ at room temperature, the samples were transferred to $10 \mathrm{ml}$ plastic centrifuge tubes and the cell debris was removed by centrifugation. The absorbance of each sample at $568 \mathrm{~nm}$ was then determined in a stoppered glass cuvette. This assay was found to be linear for assay times of up to at least $45 \mathrm{~min}$, for $A_{568}$ up to at least 0.8 and for sample size up to at least $500 \mu$ l. One unit of tryptophanase is defined as that which will convert $1 \mathrm{nmol} \mathrm{L-tryptophan} \mathrm{to} \mathrm{indole} \mathrm{in} 1 \mathrm{~min}$. Cell protein concentrations were estimated from the $A_{600}$ at the time of sampling by reference to a standard curve, constructed by drying to constant weight samples of known $A_{600}$.

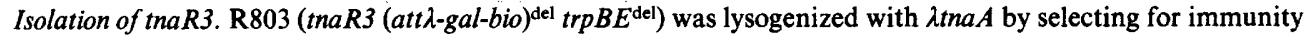
to גimm 21 clear. One purified lysogen was induced by UV irradiation and the resulting lysate was used to transduce MY281 (tra2 (tonB-trpAC9) del) to $\mathrm{Tna}^{+}$. Out of 51 transductants tested, $27 \mathrm{grew}$ on glycerol/indole/minimal medium and had therefore acquired $\lambda$ tnaR3. A putative MY281 ( $\lambda$ tnaR3) lysogen was purified and used to prepare a lysate. This lysate was then used to transduce MY281 to Tna ${ }^{+}$. All 850 of these transductants were found, by replication to glycerol/indole/minimal medium, to have the TnaR3 phenotype. The purified $\lambda$ tnaR3 was maintained as an R103 ( $\lambda$ tnaR3) lysogen.

Construction of R128 (tnaR3 tnaAts6). This construction was performed in two stages. We first isolated a tnaR3 tna ${ }^{-}$derivative by using localized mutagenesis. A P1 lysate prepared on MEB67 (tnaR3 bglR (tonB$\operatorname{trp} A C 9)^{\text {del) }}$ ) was mutagenized with hydroxylamine as described previously (White \& Yudkin, 1979). This was used to transduce R103 (tnaR3 $\mathrm{bgl} \mathrm{R}^{+}$) to growth on salicin $(\mathrm{bglR})$. The transductants were then replicated to 
Table 1. Strains of bacteria used in this work

All strains are $E$. coli $\mathrm{K} 12$ derivatives. The specialized transducing phage $\lambda$ imm 21 tna (here called $\lambda$ tna) was the gift of W. J. Brammar. $\lambda t n a 2$ was constructed by M. D. Yudkin by homogenotization. The construction of $\lambda$ tnaR3 is described in the text. To avoid confusion the tna alleles carried by $\lambda$ tna in strains lysogenic for this phage and its derivatives are described fully.

Strain

W3110

AC9

MY281

MY355

MY634

MY1396

D3

ts6

HVT7

HVT25

R100

R103

R126

R128.

R200

R203

R225

R226

R228

R303

R325

R326

R328

R403

R500

R525

R803

RA110

MEB65

MEB67

MEB70

MEB86
Genotype

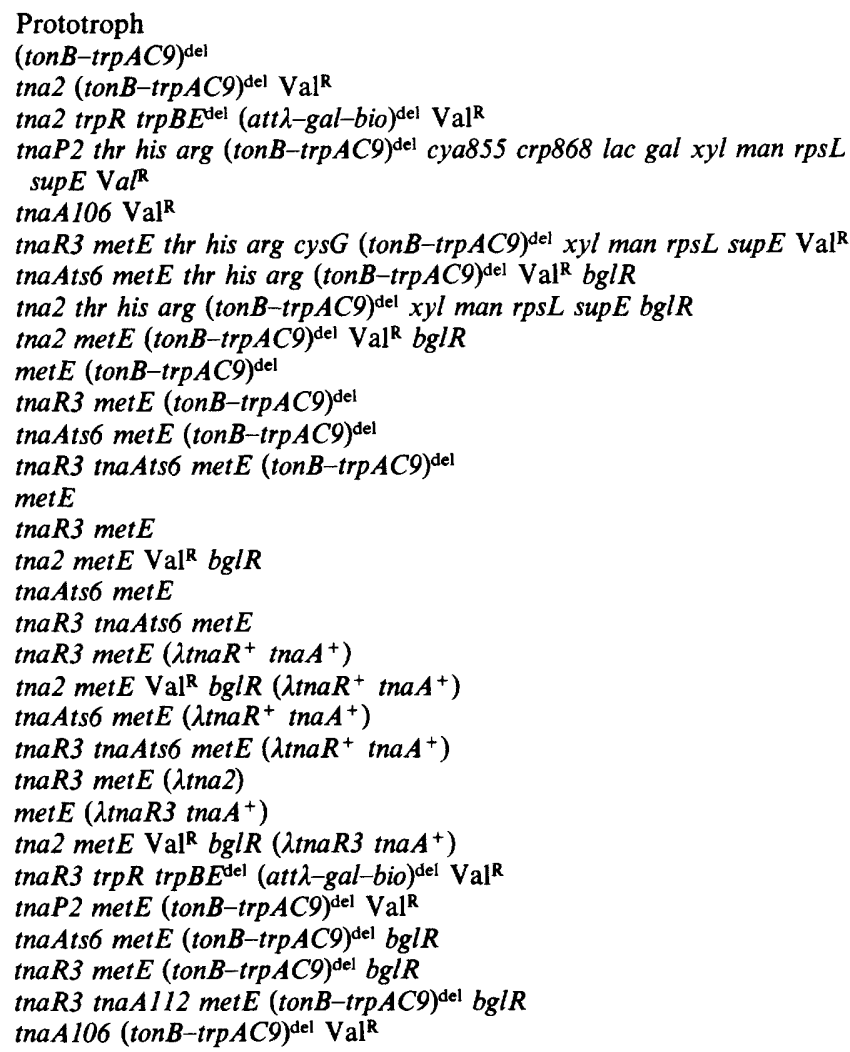

\section{Source}

C. Yanofsky

C. Yanofsky

This laboratory

This laboratory

This laboratory

This laboratory

This laboratory

This laboratory

This laboratory

This laboratory

HVT25 × P1(W3110)

HVT25 × P1(D3)

HVT25 × P1(ts6)

See text

R100 × P1(W3110)

$\mathrm{R} 103 \times \mathrm{P} 1(\mathrm{~W} 3110)$

HVT25 $\times$ P1(W3110)

R126 × P1(W3110)

R128 × P1(W3110)

$\mathrm{R} 203 \times \lambda$ tna

$\mathrm{R} 225 \times \lambda$ tna

$\mathrm{R} 226 \times \lambda$ tna

$\mathrm{R} 228 \times \lambda$ tna

$\mathrm{R} 203 \times \lambda$ tna 2

$\mathrm{R} 200 \times \lambda$ tnaR 3

$\mathrm{R} 225 \times \lambda$ tnaR3

MY355 × P1(R103)

HVT25 × P1(MY634)

R126 $\times$ P1(HVT7)

R103 × P1(HVT7)

See text

AC9 $\times$ P1(MY1396)

salicin/indole/5-methyl-DL-tryptophan medium to detect Tna- colonies. We found $21 / 5000$ transductants that failed to grow on this medium. Three were eventually found to be tna. One of these mutants, MEB70, lacked detectable tryptophanase activity. Tna ${ }^{+}$revertants of MEB70 were found to have retained their tryptophanaseconstitutive phenotype.

MEB70 (tnaR3 tna $^{-}$) was transduced to growth at $30^{\circ} \mathrm{C}$ on glycerol/indole/5-methyl-DL-tryptophan, supplemented with $20 \mu \mathrm{L}$ broth per plate, with P1 grown on MEB65 (tnaR ${ }^{+}$tnaAts6). This procedure allows the selection of both $\mathrm{Tna}^{+}$and $\mathrm{Tna}^{\mathrm{ts} 6}$. Transductants were replicated to glycerol/indole/minimal medium supplemented with $50 \mu \mathrm{g} \mathrm{L}$-cysteine $\mathrm{ml}^{-1}$ and incubated at $30{ }^{\circ} \mathrm{C}$ for $7 \mathrm{~d}$. The L-cysteine was added to stimulate growth of constitutive strains on glycerol/indole medium (see Results). The prolonged incubation of the replicas was to allow any tnaR3 tnaAts6 recombinants to grow. We obtained 19 tnaR3 recombinants out of 750 colonies replicated. Of these one grew on glycerol/indole/5-methyl-DL-tryptophan at $30^{\circ} \mathrm{C}$ but not at $40^{\circ} \mathrm{C}$. This recombinant failed to grow on glycerol/indole/minimal medium at any temperature tested. When tested on glycerol/indole medium supplemented with $50 \mu \mathrm{g} \mathrm{S}$-benzyl-L-cysteine $\mathrm{ml}^{-1}$ (which we had previously found to enhance growth of constitutive strains on glycerol/indole medium but to have no stimulatory effect on inducible strains - see Results) it behaved as expected for a tnaR3 tnaAts6 derivative. That is, it grew on glycerol/indole/5methyl-DL-tryptophan or glycerol/indole/S-benzyl-L-cysteine media at $30^{\circ} \mathrm{C}$ but not at $40^{\circ} \mathrm{C}$. Strain $\mathrm{R} 126\left(\right.$ tna $R^{+}$ tnaAts6), on the other hand, grew at $30^{\circ} \mathrm{C}$ on glycerol/indole/5-methyl-DL-tryptophan medium but not on glycerol/indole $/ S$-benzyl-L-cysteine medium, and at $40^{\circ} \mathrm{C}$ grew on neither medium. Both strains grew on glycerol/indole medium supplemented with L-tryptophan at both $30^{\circ} \mathrm{C}$ and $40^{\circ} \mathrm{C}$, and $\mathrm{R} 103\left(\operatorname{tnaR3} \operatorname{tnaA} A^{+}\right)$grew on all these media at both $30^{\circ} \mathrm{C}$ and $40^{\circ} \mathrm{C}$. Subsequent enzyme assays demonstrated the thermolabile constitutive expression of tryptophanase in strain R228 (the $t r p^{+}$derivative of R128) - see Results. 


\section{RESULTS}

\section{Mapping of tnaR3}

Taylor \& Yudkin (1978) have shown that the mutation tnaR3 is more than $98 \%$ co-transduced by $\mathrm{P} 1$ phage with tnaAts6, a tryptophanase structural gene mutation, and suggested that it was on the side of tnaA distant from $b g l R$. We have confirmed this conclusion by mapping tnaR3 against tnaA106 which, of all the tnaA mutations isolated by White \& Yudkin (1979), maps furthest from $b g l R$.

P1 grown on MEB67 (tnaR3 bglR trp AC9) was used to transduce MEB86 (tnaAl06 bglR ${ }^{+}$ $\operatorname{trp} A C 9)$ to $\mathrm{Tna}^{+}$with selection on glycerol/indole/5-methyl-DL-tryptophan. The tna $A^{+}$ transductants were replica plated to glycerol/indole plates to identify tna $R^{+}$recombinants. Out of $5000 \mathrm{tnaA}^{+}$transductants, $13(0.3 \%)$ were tha $R^{+}$. Of these 13 recombinants 9 were $b g l R$ (donor type). Since the expected frequency of co-transduction between $b g l R$ and $\operatorname{tn} a A$ is $70 \%$, we conclude that only a single cross-over event is required to give $t n a R^{+} t n a A^{+} b g l R$ recombinants and hence that the order of these three markers is tnaR3-tnaAl06-bglR.

\section{Behaviour of strain R103 on selective media}

We found that strain R103 (tnaR3 $\operatorname{trp} A C 9$ del) grew much more slowly on glycerol/indole/minimal medium than on the same medium supplemented with 5-methyl-DL-tryptophan, or with Ltryptophan. Yet Taylor \& Yudkin (1978) had reported that the mutation tnaR3 renders tryptophanase synthesis constitutive at about $80 \%$ of the fully induced wild-type rate. It was therefore difficult to understand why R 103 should grow better on glycerol/indole/5-methyl-DLtryptophan medium than on glycerol/indole medium.

We could readily isolate derivatives of strain $\mathrm{R} 103$ which grew well on glycerol/indole medium; these proved to be resistant to catabolite repression as well as being higher-level constitutives. Moreover, the catabolite-resistant promoter mutant RA110 (tnaP2 trpAC 9 del) (Ward \& Yudkin, 1976) which is also constitutive for tryptophanase synthesis, grew better than R103 on glycerol/indole medium despite the fact that it is a lower-level constitutive.

These observations implicate catabolite repression as a cause of the difference in growth rates between R103 growing on glycerol/indole/5-methyl-DL-tryptophan and glycerol/indole media. Catabolite repression might result from a restriction in growth imposed by limitation of tryptophan; but the question still remains why tryptophan should become limiting in the first place. We suggest that the ability of tryptophanase to synthesize L-tryptophan is enhanced in the presence of 5-methyl-DL-tryptophan. This could be explained if 5-methyl-DL-tryptophan were an allosteric activator of tryptophanase, but no such interaction has been reported. We favour the hypothesis that the reaction leading to L-tryptophan on glycerol/indole medium is different to that taking place in the presence of 5-methyl-DL-tryptophan. It is known (Snell, 1975) that tryptophanase will catalyse replacement reactions of the type:

$$
\text { R. } \mathrm{CH}_{2} \cdot \mathrm{CH} \cdot \mathrm{NH}_{2} \cdot \mathrm{COOH}+\text { indole } \rightleftharpoons \mathrm{R} \cdot \mathrm{H}+\text { L-tryptophan }
$$

and that the kinetic parameters for this reaction are more favourable to the synthesis of L-tryptophan than are those for the reverse of the normal tryptophanase reaction (see Introduction) which we have hitherto assumed to be the route of L-tryptophan synthesis under these selective conditions.

To test this hypothesis we examined a number of different compounds that are substrates for the replacement reaction but do not induce tryptophanase, to see whether they would stimulate growth of R103 on glycerol/indole medium. The data presented in Table 2 show that some of these compounds do indeed have such an effect. One of these substrates, $S$-methyl-L-cysteine, even allowed strain AC9 ( $\operatorname{tna} R^{+} \operatorname{trp} A C 9$ ) to grow on glycerol/indole medium. We assume that this is because $S$-methyl-L-cysteine is such a good substrate for the replacement reaction that even uninduced levels of tryptophanase can provide sufficient L-tryptophan for growth under these conditions. Another compound, $S$-benzyl-L-cysteine, allowed the clearest distinction to be made butween constitutive and non-constitutive strains on glycerol/indole medium. 
Table 2. Growth of R103 and AC9 on glycerol/indole/minimal medium supplemented with replacement-reaction substrates

Strains $\mathrm{R} 103$ (tnaR3 trp $\left.A C 9^{\mathrm{del}}\right)$ and $\mathrm{AC9}\left(\right.$ tnaR ${ }^{+}$trp $\left.A C{ }^{\mathrm{del}}\right)$ were streaked on glycerol $/ \mathrm{minimal}$ medium supplemented with indole at $5 \mu \mathrm{g} \mathrm{ml}^{-1}$ and potential replacement-reaction substrates at $50 \mu \mathrm{g} \mathrm{ml}^{-1}$. Growth was scored after $48 \mathrm{~h}$ incubation at $37^{\circ} \mathrm{C} .++$, Colonies about $1 \mathrm{~mm}$ diameter; ++++ , colonies about $3 \mathrm{~mm}$ diameter; - , no growth visible.

\begin{tabular}{|c|c|c|c|}
\hline \multirow[b]{2}{*}{ Supplement } & \multirow[b]{2}{*}{ Strain } & \multicolumn{2}{|c|}{ Growth } \\
\hline & & $\mathrm{AC} 9$ & R103 \\
\hline $\begin{array}{l}\text { 5-Methyl-DL-tryptophan } \\
\text { L-Phenylalanine }\end{array}$ & & $\begin{array}{c}+++ \\
-\end{array}$ & $\begin{array}{c}+++ \\
-\end{array}$ \\
\hline$S$-Methyl-L-cysteine & & ++ & ++++ \\
\hline$S$-Ethyl-L-cysteine & & - & ++++ \\
\hline$S$-Benzyl-L-cysteine & & - & +++ \\
\hline L-Cysteine & & - & +++ \\
\hline
\end{tabular}

These findings lead us to suggest that the selection used by Taylor \& Yudkin (1978) in the selection of tna constitutive mutants, namely the plating of $\operatorname{tnaA^{+}} \operatorname{trp} A C 9$ strains on glycerol/indole medium, was too severe. This might account for the apparently low frequency of constitutive mutants obtained. In addition, the fact that all of the second-step mutations leading to improved growth of constitutive mutants on glycerol/indole medium resulted in the strains' becoming resistant to catabolite repression implies that this selection will introduce a bias against ordinary constitutive mutations. Indeed it may well be that the only reason why Taylor \& Yudkin isolated some constitutive mutants that were not resistant to catabolite repression was that their selections were made from $\mathrm{Cys}^{-}$strains and were therefore performed in medium supplemented with L-cysteine. L-Cysteine is another substrate for the replacement reaction and Table 2 shows that L-cysteine stimulates the growth of R103 on glycerol/indole medium.

\section{Tryptophanase expression in $R 203$}

The mutation tnaR3 renders tryptophanase expression constitutive. Taylor \& Yudkin (1978) have reported that in the absence of L-tryptophan, tnaR 3 tnaA $A^{+}$strains synthesize tryptophanase at a differential rate that is $80 \%$ of the fully induced wild-type and that this rate of synthesis is unaffected by the addition of L-tryptophan. We now wish to amend these findings in two respects.

(a) The previous observations were made with a whole-cell assay for tryptophanase. When we used toluene-treated cells for the assay we found that the differential rates we obtained for wildtype strains fully induced for tryptophanase were five to ten times higher. The constitutive rate of tryptophanase synthesis obtained for strain R203 ( $\operatorname{tnaR} 3 \operatorname{trp}^{+}$) was unaffected by the change in assay. We suspect that L-tryptophan uptake is rate-limiting in the whole-cell assay of the fully induced wild-type (Edwards \& Yudkin, 1982).

(b) The addition of L-tryptophan to cultures of R203 growing on glycerol/minimal medium represses tryptophanase synthesis by about $20 \%$ (data not shown). We interpret this as selfcatabolite repression (Katz \& Englesberg, 1971) of tryptophanase synthesis by the pyruvate released in the tryptophanase reaction [a combination of glycerol and pyruvate as carbon source is known to repress tryptophanase synthesis severely (McFall \& Mandelstam, 1963; Sato et al., 1969)]. In support of this hypothesis we found that repression of tryptophanase synthesis by Ltryptophan in R203 did not occur when pyruvate replaced glycerol as sole carbon source. Furthermore, the repeated addition of small amounts of pyruvate to cultures of R203 grown in glycerol/minimal medium could mimic the repression of tryptophanase synthesis by Ltryptophan (data not shown).

Using the amended assay described in Methods, we found that strain R200 ( $\operatorname{tna} R^{+} \operatorname{tnaA^{+}}$ ), when grown at $37^{\circ} \mathrm{C}$ in minimal medium containing $1 \%$ pyruvate as carbon source and $100 \mu \mathrm{g}$ L-tryptophan $\mathrm{ml}^{-1}$, synthesized tryptophanase at a differential rate of 1000 to 1100 units (mg protein) ${ }^{-1}$. When grown in the same medium with or without tryptophan, strain R203 
Table 3. Differential rates of tryptophanase synthesis

The cultures were grown at $30^{\circ} \mathrm{C}$ in minimal medium supplemented with $1 \%$ pyruvate. Where indicated, cultures were induced for tryptophanase synthesis by the addition of $500 \mu \mathrm{g} \mathrm{L}$-tryptophan $\mathrm{ml}^{-1}$.

\begin{tabular}{|c|c|c|c|}
\hline \multirow[b]{2}{*}{ Strain } & \multirow[b]{2}{*}{ Genotype } & \multicolumn{2}{|c|}{$\begin{array}{l}\text { Differential rate of } \\
\text { tryptophanase synthesis } \\
\text { [units (mg protein })^{-1} \text { ] }\end{array}$} \\
\hline & & - Tryptophan & + Tryptophan \\
\hline R200 & $\operatorname{tn} a R^{+} \operatorname{tn} a A^{+}$ & $<20$ & 415 \\
\hline R325 & $\operatorname{tnaR} R^{+} \operatorname{tna} 2 / \lambda \operatorname{tna} R^{+} \operatorname{tna} A^{+}$ & $<20$ & 320 \\
\hline R203 & $\operatorname{tnaR3} \operatorname{tnaA^{+}}$ & 208 & 220 \\
\hline R403 & $\operatorname{tnaR} 3 \operatorname{tnaA}^{+} / \lambda \operatorname{tnaR} R^{+} \operatorname{tna} 2$ & 183 & 203 \\
\hline R525 & $\operatorname{tnaR}^{+} \operatorname{tna} 2 / \lambda \operatorname{tnaR} 3$ tnaA $A^{+}$ & 137 & 154 \\
\hline R303 & $\operatorname{tnaR3} \operatorname{tnaA^{+}} / \lambda \operatorname{tnaR^{+}} \operatorname{tnaA}^{+}$ & 220 & 544 \\
\hline R500 & $\operatorname{tnaR^{+}} \operatorname{tnaA}^{+} / \lambda \operatorname{tnaR} 3$ tnaA $^{+}$ & 174 & 656 \\
\hline
\end{tabular}

(tnaR3 tnaA $^{+}$) synthesized tryptophanase at a differential rate of 290 units (mg protein) ${ }^{-1}$. Hence our revised estimate of the degree of constitutivity conferred by tnaR3 is about $30 \%$ of the fully induced wild-type.

\section{Dominance studies with $\lambda$ tna}

tnaR3 is cis-dominant. The fact that we were able to construct derivatives of $\lambda$ tna that carried tnaR 3 and that transduced $t n a R^{+}$strains to constitutivity (see Methods) strongly suggests that the tnaR locus is carried on $\lambda$ tna. In diploids of the type tna $R^{+}$tna2/tnaR3 tna $A^{+}$we found that tryptophanase was constitutive and not further inducible (see Table 3) regardless of whether the tnaR 3 allele was carried on the $\lambda$ tna or on the bacterial chromosome. We conclude that tnaR3 is at least cis-dominant.

tnaR 3 is not trans-dominant. The results described above suggest that tna $R^{+}$is not dominant to tnaR3. We now ask whether $t$ tnaR3 is dominant to tna $R^{+}$. The assay results shown in the last two lines of Table 3 show that in diploids of the type $\operatorname{tnaR}^{+}$tnaA $A^{+} /$tnaR3 tnaA $^{+}$there is both an inducible and a constitutive component to the expression. This implies that the effect of tnaR3 is not to render tnaA expression constitutive in trans. It is possible, however, that some form of codominance is operating, i.e. that when $\operatorname{tnaR}^{+}$and tnaR 3 are both present, expression from both tna $A$ genes is partly constitutive and partly inducible. The alternative explanation is that constitutive expression can occur only from the tnaA gene in cis to tnaR3. To distinguish between these two possibilities we constructed a strain in which tnaR3 was in cis to the temperaturesensitive lesion tnaAts6 (see Methods), and introduced $\lambda t n a R^{+}$tna $A^{+}$into this strain to form a

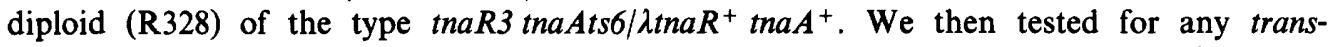
dominance of tnaR3 by looking for constitutive expression of tryptophanase at $42{ }^{\circ} \mathrm{C}$. Since tnaAts 6 renders tyrptophanase inactive at this temperature, constitutive expression should only be observed if tnaR 3 were making the $\operatorname{tnaA}^{+}$allele partially constitutive in trans. We therefore assayed the diploid (R328) along with suitable controls at $42{ }^{\circ} \mathrm{C}$ in the presence or absence of L-tryptophan (Table 4). We consistently failed to find any evidence for constitutive expression at $42^{\circ} \mathrm{C}$ in the diploid $\mathrm{R} 328$.

It remained a possibility, however, that there was a low level of heat-stable constitutive expression in this strain caused by a weak trans effect of tnaR3. We ruled out this possibility by performing assays that utilized a larger sample of cells $(5 \mathrm{ml})$ and that were correspondingly more sensitive. The data presented in Table 5 show that for R328 the differential rate of tryptophanase synthesis at $42^{\circ} \mathrm{C}$ in the absence of L-tryptophan is no greater than the sum of expression from R326 and R228. We therefore conclude that tnaR3 has no effect on tnaA expression in trans.

We were surprised to find that the rate of synthesis of tryptophanase was strongly affected by temperature even in the wild-type R200. Tryptophanase synthesis in R203 (tnaR3) is much less 
Table 4. Differential rates of tryptophanase synthesis

The cultures were grown in minimal medium with $1 \%$ pyruvate as carbon source. A single colony of each strain was picked into $10 \mathrm{ml}$ of the minimal medium which was then divided for overnight incubation at $30^{\circ} \mathrm{C}$ and $42^{\circ} \mathrm{C}$. The overnight cultures were used to inoculate fresh media at the appropriate temperature. Where indicated $(+)$ the cultures were induced for tryptophanase expression by the addition of $500 \mu \mathrm{g}$ L-tryptophan $\mathrm{ml}^{-1}$.

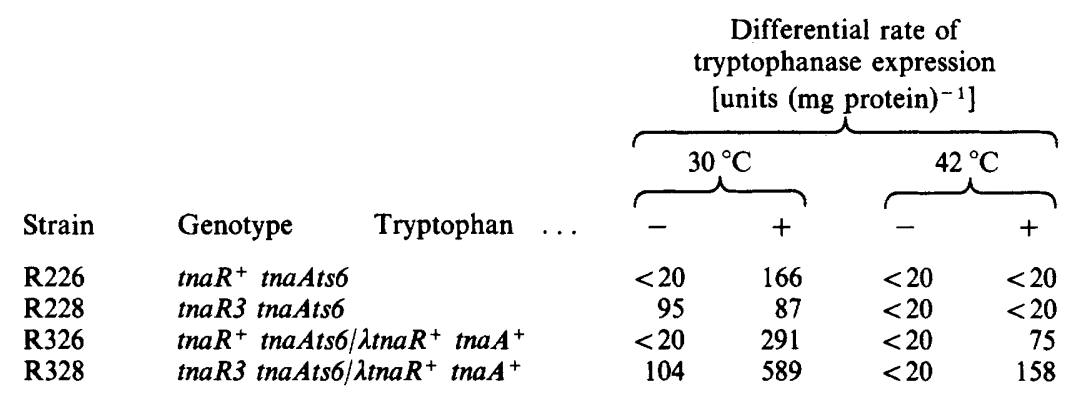

\section{Table 5. Tryptophanase synthesis in strain R328}

The medium used was as described in the legend to Table 4 . The cultures were grown at $42{ }^{\circ} \mathrm{C}$ in the absence of inducer and $5 \mathrm{ml}$ samples were taken periodically for assay.

Differential rate of tryptophanase synthesis

Strain Genotype $\quad$ [units (mg protein) ${ }^{-1}$ ]
(mis

\begin{tabular}{|c|c|}
\hline R228 & $\operatorname{tna} R 3$ tnaAts 6 \\
\hline R326 & $\operatorname{tnaR}^{+}$tnaAts $6 / \lambda \operatorname{tn} a R^{+} \operatorname{tnaA}^{+}$ \\
\hline R328 & 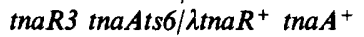 \\
\hline
\end{tabular}

Table 6. Effect of growth temperature on the apparent degree of constitutivity conferred by tnaR3

Single colonies of R203 ( $\operatorname{tnaR3} \mathrm{tnaA}^{+}$) and R200 ( $\operatorname{tnaR^{+}} \mathrm{tnaA}^{+}$) were picked into minimal medium supplemented with $1 \%$ pyruvate. Each culture was divided into three for overnight incubation at $30^{\circ} \mathrm{C}$, $37^{\circ} \mathrm{C}$ and $42^{\circ} \mathrm{C}$. The cultures were then diluted into fresh medium at the appropriate temperature. The cultures of R200 were induced by the addition of $500 \mu \mathrm{g} \mathrm{L-tryptophan} \mathrm{ml}^{-1}$.

$\begin{array}{ccc}\begin{array}{c}\text { Growth } \\ \text { temperature }\end{array} & \begin{array}{c}\text { R200 } \\ \text { (+ Tryptophan) } \\ \text { [units (mg protein) }\end{array} & \begin{array}{c}\text { R203 } \\ \text { (-Tryptophan) }\end{array} \\ 30^{\circ} \mathrm{C} & 455 & 227 \\ 37^{\circ} \mathrm{C} & 1000 & 290 \\ 42^{\circ} \mathrm{C} & 79 & 149\end{array}$

sensitive to temperature. Table 6 shows the apparent degree of constitutivity exhibited by R203 at different temperatures. We have no convincing explanation for this effect but it does not affect the foregoing argument about the lack of trans-dominance of tnaR3.

\section{DISCUSSION}

Taylor \& Yudkin (1978) found that plating a trp-deleted $t \mathrm{naA}^{+}$strain on glycerol/indole/minimal medium yields spontaneous tna constitutive mutants at a very low frequency $\left(<10^{-10}\right)$. We have previously taken this result to mean that control of tryptophanase synthesis does not operate by a simple repressor mechanism. Our finding that the above selection is more severe 
than we had supposed perhaps explains the low frequency at which constitutive mutants were isolated.

The mutation tnaR 3 renders tryptophanase synthesis constitutive at a differential rate $30 \%$ of that observed for the fully induced wild-type at $37^{\circ} \mathrm{C}$. It is cis-dominant but does not render a tna $A$ allele constitutive in trans. It is situated very close to tna $A$ on the side of tnaA distant from $b g l R$. These findings are consistent with thaR 3 being either an operator mutation that prevents binding of a repressor protein (compare $l a c O^{\mathrm{c}}$ ) or else a mutation rendering tryptophanase synthesis independent of a positive regulator (compare $\mathrm{araI}^{\mathrm{c}}$ ). It is interesting to note that ara $\mathrm{I}^{\mathrm{c}}$ mutants readily undergo second-step events to give the catabolite-insensitive ara $X^{\mathrm{c}}$ mutants (Colome et al., 1977). However, it cannot be altogether ruled out that thaR is the gene for a regulator (RNA or protein), which acts only in cis because of restrictions of stability or diffusion.

An intriguing feature of this study was the finding that tna $A$ expression is temperature sensitive in $t n a R^{+}$but not in $t n a R 3$ strains. We have no convincing explanation of this finding.

The results presented in this paper should lead to an improved selection for tryptophanase constitutive mutants. For example, glycerol/indole/minimal medium supplemented with Lcysteine or $S$-benzyl-L-cysteine will allow the growth of constitutive mutants but not of the wildtype. We hope that the elucidation of the selections used to isolate regulatory mutants may lead to the isolation of mutations that will improve our understanding of the mechanism of regulation of tryptophanase synthesis, which at present remains obscure.

R. M. Edwards gratefully acknowledges the receipt of a Science Research Council Scholarship for training in research methods.

\section{REFERENCES}

Borck, K., Beggs, J. D., Brammar, W. J., Hopkins, A. S. \& MurRay, N. E. (1976). The construction in vitro of transducing derivatives of phage lambda. Molecular and General Genetics 146, 199-207.

Colome, J., Wilcox, G. \& Englesberg, E. (1977). Constitutive mutations in the controlling site region of the $\operatorname{araBAD}$ operon of Escherichia coli $\mathrm{B} / \mathrm{r}$ that decrease sensitivity to catabolite repression. Journal of Bacteriology 129, 948-958.

DeEley, M. C. \& YanofSKY, C. (1981). Nucleotide sequence of the structural gene for tryptophanase of Escherichia coli K-12. Journal of Bacteriology 147, 787-796.

DeEley, M. C. \& YanofsKy, C. (1982). Transcription initiation at the tryptophanase promoter of Escherichia coli K-12. Journal of Bacteriology 151, 942-951.

EDWARDS, R. M. \& YUdKIN, M. D. (1982). Location of the gene for the low-affinity tryptophan-specific permease of Escherichia coli. Biochemical Journal 204, 617-619.

KATZ, L. \& ENGLESBERG, E. (1971). Hyperinducibility as a result of mutation in structural genes and selfcatabolite repression in the ara operon. Journal of Bacteriology 107, 34-52.

McFall, E. \& Mandelstam, J. (1963). Specific metabolic repression of three induced enzymes in Escherichia coli. Biochemical Journal 89, 391-397.

PeCK, R. M., Markey, F. \& Yudkin, M. D. (1971). Effect of 5-fluorouracil on $\beta$-galactosidase synthesis in an Escherichia coli mutant resistant to catabolite repression of the lac operon. FEBS Letters 16, 43-44.
Sato, T., AIda, K. \& Uemura, T. (1969). Contribution of glycolysis to catabolite repression of L-tryptophanase synthesis in Escherichia coli. Journal of General and Applied Microbiology 15, 109-121.

SNELL, E. E. (1975). Tryptophanase: structure, catalytic activities, and mechanism of action. Advances in Enzymology 42, 287-333.

TAYLOR, H. V. \& YUdKIN, M. D. (1978). Synthesis of tryptophanase in Escherichia coli: isolation and characterization of a structural gene mutant and two regulatory mutants. Molecular and General Genetics 165, 95-102.

VOGEL, H. J. \& BONNER, D. M. (1956). Acetylornithinase of Escherichia coli: partial purification and some properties. Journal of Biological Chemistry 218, 97106.

WARD, D. F. \& YUDKIN, M. D. (1976). Mutations in Escherichia coli that relieve catabolite repression of tryptophanase synthesis. Tryptophanase promoterlike mutations. Journal of General Microbiology 92, 133-137.

WhITE, M. K. \& YudKIN, M. D. (1979). Complementation analysis of eleven tryptophanase mutations in Escherichia coli. Journal of General Microbiology 114, 471-475.

YudKIN, M. D. (1976). Mutations in Escherichia coli that relieve catabolite repression of tryptophanase synthesis. Mutations distant from the tryptophanase gene. Journal of General Microbiology 92, 125-132. 